\title{
CRESCIMENTO ECONÔMICO NOS MUNICÍPIOS DE ALAGOAS ENTRE 2000 E 2015: UMA APLICAÇÃO DE PAINEL DINÂMICO'
}

\author{
Tallyna Tellys de Sousa Moura² \\ Thierry Molnar Prates ${ }^{3}$ \\ Alexandra Maria Rios Cabral ${ }^{4}$
}

\begin{abstract}
0 artigo investiga as razões para o crescimento econômico dos municípios de Alagoas, com especial atenção à participação dos gastos e da arrecadação. Adotou-se a proposta da teoria de crescimento endógeno e da nova geografia econômica. 0 corte temporal se estende de 2000 a 2015, pela disponibilidade de informações. Os resultados foram alcançados procedendo-se à regressão do painel de dados nos métodos de efeito fixo e para generalized method of moments (GMM), nas formas difference e system. No que concerne aos resultados obtidos, evidências corroboram a suposição teórica de efeitos positivos em algumas das variáveis sobre o crescimento econômico, como a proporção do produto interno bruto (PIB) industrial no PIB de certa localidade, o PIB defasado em um ano e a densidade demográfica. Ou seja, a presença de aglomerados industriais em centros mais populosos exerce forças centrípetas, favorecendo a redução de custos e a troca de informações, com o estímulo à entrada de novas empresas e à geração de emprego e renda.
\end{abstract}

Palavras-chave: gastos governamentais; crescimento econômico; economias de aglomeração; GMM; Alagoas.

\section{ECONOMIC GROWTH IN ALAGOAS MUNICIPALITIES BETWEEN 2000 AND 2015: A DINAMIC PANEL APPLICATION}

The article explores the reasons for economic growth in the municipalities of Alagoas from 2000 to 2015, with special attention to the participation of government expenditures and revenues. The endogenous growth and the new economic geography theory were adopted. The results were achieved by using panel data on fixed-effect methods and Generalized Method of Moments in Difference and System forms. Evidences corroborate the theoretical positive effects assumption of some variables on the economic growth, as the proportion of the industrial GDP in total GDP, the GDP lagged in one year and the population density. Therefore, the presence of industrial clusters in crowded centers, works as centripetal forces, favoring costs reduction and information exchange, and boosting new companies entry and employment and income generation.

Keywords: government expenditure; economic growth; agglomeration economies; GMM; Alagoas.

\section{CRECIMIENTO ECONÓMICO EN LAS MUNICIPALIDADES DE ALAGOAS ENTRE 2000 Y 2015: UNA APLICACIÓN DE PANEL DINÁMICO}

El artículo explora las razones del crecimiento económico en los municipios de Alagoas de 2000 a 2015, con atención especial a la participación de los gastos y recaudación del gobierno. Se adoptó el crecimiento endógeno y la nueva teoría de la geografía económica. Los resultados se lograron

1. DOI: http://dx.doi.org/10.38116/ppp54art02

2. Mestre em economia aplicada pela Universidade Federal de Alagoas (Ufal).E-mail: <tallynatellys@hotmail.com>.

3. Professor associado da Universidade Federal Rural do Rio de Janeiro (UFRRJ).E-mail: <thierry_prates@hotmail.com>.

4. Professora adjunta da Ufal. E-mail: <alexandra.cabral@feac.ufal.br>. 
mediante el uso de datos de panel sobre métodos de efectos fijos y Método generalizado de momentos en diferencias y formas del sistema. Las evidencias corroboran el supuesto de efectos positivos teóricos de algunas variables sobre el crecimiento económico, como la proporción del PIB industrial en el PIB total, el PIB rezagado en un año y la densidad de población. Por lo tanto, la presencia de conglomerados industriales en centros atestados funciona como fuerzas centrípetas, lo que favorece la reducción de costos y el intercambio de información, e impulsa la entrada y el empleo de nuevas empresas y la generación de ingresos.

Palabras clave: gasto gubernamental; crecimiento económico; economías de aglomeración; GMM; Alagoas.

\section{CROISSANCE ÉCONOMIQUE DES MUNICIPALITÉS D'ALAGOAS ENTRE 2000 ET 2015: UNE APPLICATION DE PANNEAU DYNAMIQUE}

L'article examine les raisons de la croissance économique des municipalités d'Alagoas avec une attention particulière à la participation des dépenses et de la collecte. La théorie de la croissance endogène et la nouvelle proposition de géographie économique ont été adoptées. Le délai s'étend de 2000 à 2015, en raison de la disponibilité des informations. Les résultats ont été obtenus en régressant le panel de données dans les méthodes à effet fixe et pour la méthode généralisée des moments sous les formes Différence et Système. Dans les résultats obtenus, les preuves corroborent I'hypothèse théorique d'effets positifs sur certaines des variables de la croissance économique, telles que: la proportion du PIB industriel dans le PIB de cette localité, le PIB décalé d'un an et la densité démographique. En d'autres termes, la présence de grappes industrielles dans des centres plus peuplés exerce des forces centripètes, favorisant la réduction des coûts et l'échange d'informations, stimulant l'entrée de nouvelles entreprises et la création d'emplois et de revenus.

Mots-clés: dépenses publiques; croissance économique; I'épargne d'agglomération; GMM; Alagoas.

JEL: E62; H50; H71; C23, 047.

\section{INTRODUÇÃO}

$\mathrm{O}$ crescimento econômico de uma regiáo está fortemente atrelado à capacidade local de manter a produtividade elevada. Isso ocorre de diversas maneiras; uma delas é o incentivo governamental, que provoca estímulos econômicos para a produção, os quais geram efeitos multiplicadores que se espalham por toda a economia. Ademais, sabe-se que o objetivo do desenvolvimento econômico é atingir e tornar sustentável um alto padrão de vida para os cidadãos. Elevar o padrão de vida depende também do aumento da produtividade e do crescimento, que, por sua vez, é consequência direta do desempenho da inovação.

Ao longo dos anos, a literatura tem destacado a importância das políticas do governo como indutoras do crescimento econômico (Solow, 1956; Barro, 1990; Krugman, 1991; Silva, Cruz e Irffi, 2013, entre muitos outros). Nessa linha de análise, este artigo pretende estimar a participação da política fiscal local, e de alguns outros indicadores, no crescimento econômico dos municípios do estado de Alagoas de 2000 a 2015. 
Para essa estimação, foi elaborado um modelo baseado em Barro (1990) e Krugman (1991), utilizando-se em conjunto os conhecimentos desenvolvidos pela teoria de crescimento econômico e pela nova geografia econômica (NGE). Adota-se como referência o estudo econométrico realizado por Costa, Lima e Silva (2014), com o intuito de se verificar a magnitude do impacto do gasto e da receita com tributação na variável crescimento econômico.

O objetivo principal do trabalho é testar a capacidade da política fiscal como instrumento indutor do crescimento econômico do estado de Alagoas, Unidade da Federação (UF) que, por inúmeras razóes regionais, geoeconômicas e populacionais, difere das macrorregióes do país e das demais UFs. A escolha de Alagoas deve-se à necessidade de políticas diversas para promoção do crescimento, em virtude da situação de pobreza e atraso de grande parte do estado.

Assim, devido aos problemas estruturais encontrados no estado, como ter o vigésimo quinto PIB per capita no Brasil (IBGE, 2015), é lícito se realizar uma análise específica (e inédita) sobre Alagoas, a fim de contribuir para a diminuição das desigualdades regionais e a economia dos escassos recursos públicos disponíveis.

Além desta introdução, o estudo subdivide-se em mais cinco seçôes. $\mathrm{Na}$ segunda seção, temos a revisão da literatura, em que se expóe a discussão sobre a teoria do crescimento econômico e o papel da política fiscal. Na terceira seção, faz-se referência à metodologia adotada para obtenção dos objetivos propostos, tópico em que se definem os métodos econométricos utilizados. A quarta seção traz os modelos econométricos propostos, as variáveis escolhidas e suas respectivas fontes. Na quinta, mostram-se os resultados e as análises encontrados. Por fim, na sexta e última seção, apresentam-se as consideraçóes finais.

\section{REVISÃO DA LITERATURA}

Nas últimas décadas, a partir dos anos 1980, os estudos sobre crescimento econômico vêm se multiplicando, juntamente com a preocupação, por parte dos economistas, em conhecer na prática como as políticas públicas têm impacto na economia. Essencialmente, Romer (1986) e Lucas (1988), e posteriormente Krugman (1991), reacenderam o interesse em debater o tema.

A construção dos modelos de crescimento econômico partiu do precursor modelo de crescimento exógeno apresentado por Solow (1956), o qual define que a diferença entre as rendas das regiôes pode ser explicada pela distância nas taxas de investimento, de crescimento populacional e de tecnologia. Economias com alta relação poupança/investimento tendem a ser mais ricas, por destinarem grande fração do produto e significativa parcela do tempo à acumulação de capital e qualificação, que elevam a produtividade da mão de obra. 
De acordo com o modelo, a trajetória da economia de determinada região dirige-se para um crescimento equilibrado de longo prazo. Quando esse equilíbrio é atingido, o crescimento no produto per capita só ocorre por meio da elevação do progresso tecnológico, compensando a tendência declinante do produto marginal do capital. Portanto, no longo prazo, a regiáo passa a crescer à taxa do progresso tecnológico.

Sobre o papel da política econômica de Solow, Jones (2000, p. 36) descreve dois efeitos importantes sobre o crescimento:

primeiro, as mudanças na política econômica aumentam a taxa de crescimento, mas apenas temporariamente, ao longo da trajetória de transiçáo rumo ao novo estado estacionário. Isto é, as mudanças de política não têm efeito de crescimento no longo prazo. Segundo, as mudanças na política podem ter efeitos sobre o nível. Isto é, uma mudança da política permanente pode aumentar (ou diminuir) permanentemente o nível do produto per capita.

Em síntese, segundo Solow (1956), a política econômica não afetaria a taxa de crescimento de longo prazo. Ou seja, alteraçóes nos gastos do governo e na tributação gerariam efeitos no nível do produto apenas no curto prazo.

Por sua vez, os modelos de crescimento endógeno, que construíram suas bases a partir do modelo de Solow, adicionam algumas características que permitem uma melhor explicação do crescimento de longo prazo por meio da evolução do progresso técnico, antes considerado exógeno. Abre-se, assim, espaço para ações efetivas do Estado na formulação de políticas públicas conjugadas com as ações dos agentes privados, que desempenham um papel decisivo no crescimento de longo prazo da economia.

Desse modo, considera-se que as mudanças nas políticas econômicas têm efeitos permanentes sobre o crescimento de longo prazo. Ou seja, o efeito gerado se estende até o processo de transição da trajetória de crescimento equilibrado, voltando ao nível inicial no longo prazo.

Para o modelo de crescimento endógeno do tipo AK, desconsidera-se o crescimento populacional e propóe-se que não há progresso tecnológico exógeno. Partindo-se do pressuposto de que o investimento total seja sempre maior do que a depreciação, assume-se que o estoque de capital permanecerá crescente. Com isso, considera-se que, nesse modelo, o crescimento é continuado. Isso acontece por se admitirem como constantes os retornos à acumulação de capital. Admitindo-se a taxa de crescimento como função crescente da taxa de investimento, conclui-se que políticas públicas que alterem a taxa de investimento modificarão de forma permanente a taxa de crescimento da economia. 
Assim, com o propósito de observar a participação das políticas públicas sobre o crescimento econômico, Barro (1990) agrega os gastos do governo à teoria de crescimento endógeno, considerando como fator produtivo na função de produção do modelo os serviços públicos ofertados. De modo análogo aos modelos anteriores, considera retornos constantes de escala, porém assume que cada fator isoladamente possui retornos marginais decrescentes. Então, se o governo adota um comportamento mais interventor, os indivíduos se apropriam de uma parcela menor de renda. Isso impacta de forma negativa a taxa de crescimento da economia, devido ao fato de a tributação reduzir o nível de consumo e poupança dos agentes, o que, consequentemente, reduz a acumulação de capital.

A nova geografia econômica (NGE) foi desenvolvida a partir dos trabalhos de Krugman (1991) e trouxe consigo grande contribuição às discussóes sobre crescimento econômico. A abordagem tem como propósito explicar como as atividades econômicas se ordenam no espaço, buscando entender as divergências no crescimento entre regióes e levando em conta especificidades existentes em cada uma delas. A NGE aponta, como responsáveis pelas discrepâncias do crescimento entre as regiôes, as forças que designam o agrupamento ou a dispersão das atividades econômicas, as forças centrípetas que as atraem e as forças centrífugas que as expulsam.

Sabe-se que a política fiscal, entre as políticas econômicas, é considerada um imprescindível instrumento indutor do crescimento econômico, uma ferramenta de intervenção do Estado, por meio da arrecadação de tributos e gastos do governo. O governo cobra tributos e, em contrapartida, os transforma em gastos e investimentos para atender às necessidades coletivas. Os tributos incidem sobre a renda, de forma direta ou indireta, sobre os produtos e os serviços comercializados. Se a receita é bem alocada e transformada em investimentos públicos, isto promove um efeito multiplicador; porém, quando isso não ocorre, esta ação torna-se um instrumento bloqueador do crescimento.

Os gastos do governo, tanto federais quanto estaduais e municipais, são orçados e aprovados pelos órgãos competentes em um período anterior à sua execução. O orçamento deve ser ajustado aos limites determinados por lei, e, após a sua execução, é submetido ao tribunal de contas para inspeção.

Essas despesas são fracionadas por segmentos de necessidades fundamentais, que, em alguns casos, não são ofertados pelo setor privado, a saber: saúde e saneamento, infraestrutura, habitação, previdência, educação e cultura. Quando esses recursos são gastos de forma planejada, podem gerar efeitos positivos sobre o nível do produto, direta e indiretamente. Além disso, um ambiente com melhor infraestrutura, educação e serviços públicos é capaz de atrair novos investimentos e proporcionar ainda maior crescimento. 
$\mathrm{Na}$ literatura, as discussóes sobre a importância dos gastos governamentais têm conquistado um espaço expressivo. Pesquisas nacionais e internacionais evidenciam a participação dos gastos do governo no crescimento econômico. Em estudo realizado por Aschauer (1989), por exemplo, observou-se o comportamento do setor privado dos Estados Unidos durante os anos de 1949 a 1985, a fim de se entender a queda nas taxas de crescimento da produtividade durante os anos 1970. Os resultados desse trabalho mostram a importância da participação do investimento público em infraestrutura para o crescimento econômico.

Kneller, Bleaneye e Gemmel (2001) testaram a validade do modelo de crescimento endógeno de Barro (1990) utilizando painéis de dados para os países da Organização para Cooperação e Desenvolvimento Econômico (OCDE) dos anos 1970 a 1995. Nesse trabalho, os gastos foram classificados em produtivos e improdutivos. Os resultados obtidos mostraram que gastos produtivos (educação, saúde, transporte, comunicação, defesa e habitação) são indutores do crescimento, e gastos improdutivos (previdência, assistência social etc.) geram efeitos de contração do produto.

Nota-se que alguns estudos, como os desenvolvidos por Kormendi e Meguire (1985) e Easterly e Rebelo (1993), obtiveram em seus resultados um efeito nulo para os dispêndios do governo sobre o desempenho econômico. Kormendi e Meguire (1985), por relação transversal em uma amostra de 47 países, examinaram o efeito da parcela dos gastos com consumo do governo em relação às taxas de crescimento média do PIB real, e encontraram resultados insignificantes para as despesas sobre o PIB per capita. Por seu turno, Easterly e Rebelo (1993) observaram, utilizando regressóes em cross-section, as categorias de investimentos públicos em países em desenvolvimento, e constataram que a parcela dedicada a transportes e comunicaçōes é fortemente correlacionada ao crescimento.

Desse modo, verifica-se que, no âmbito de estudos internacionais, boa parte das análises empíricas aponta para os gastos governamentais como um agente influenciador no crescimento econômico. Assim, a proposição do presente trabalho é testar localmente essa hipótese.

$\mathrm{Na}$ literatura nacional, há algumas importantes pesquisas que mostram a relação entre as despesas públicas e o produto, como o desenvolvido por Ferreira e Malliagros (1998). Uma análise empírica do setor de infraestrutura brasileira é feita para o período de 1950-1995, na qual se observa a existência de uma forte relação entre investimentos em infraestrutura (energia, telecomunicaçóes e transportes) e o crescimento econômico brasileiro.

Por outro lado, Silva, Cruz e Irffi (2013) estudaram a relação dos gastos públicos com o crescimento econômico para os municípios da Paraíba durante o período de 2000 a 2008 utilizando uma abordagem de dados em painel. 
Os resultados obtidos mostraram que as despesas com educação e cultura, saúde e saneamento e habitação e urbanismo têm baixa elasticidade-produto, influenciando de forma moderada o crescimento, enquanto os dispêndios com segurança pública, assistência e previdência e administração e planejamento não apresentaram relação com o produto.

Araújo, Monteiro e Cavalcante (2014) estudaram a relação entre os gastos públicos e o crescimento, nos municípios do Ceará, no período de 2002 a 2009, utilizando uma amostra de 122 municípios. Conjugaram uma abordagem dinâmica, como em Arellano e Bond (1991), e adotaram a função de produção de Barro (1990) como modelo teórico. Concluíram que os incrementos em capital físico e humano elevam o produto dos municípios cearenses, no entanto, o capital humano apresenta maior impacto, e por isso deveria receber maior atenção. Apontaram ainda que as despesas com saúde, saneamento e legislativos não apresentaram relação com o produto.

Costa, Lima e Silva (2014) avaliaram a importância da política fiscal local sobre o crescimento econômico dos municípios nordestinos brasileiros, assumindo como base teórica o modelo de crescimento endógeno e a NGE. A modelagem econométrica seguiu a proposta apresentada por Barro (1990), e os anos considerados na pesquisa se estenderam de 1999 a 2005. Os resultados apresentaram efeitos positivos e significativos da política fiscal sobre o crescimento econômico, destacando-se como principais fatores de explicação da taxa de crescimento do PIB per capita os gastos em educação e cultura e saúde e saneamento, juntamente com a relevância da formação de blocos industriais, medida pela produção da indústria.

Outro estudo, elaborado por Oliveira (2006), buscou captar os efeitos da política fiscal local no crescimento econômico para os municípios gaúchos no período de 1996 a 2001, e concluiu que os gastos públicos produtivos apresentaram efeitos positivos sobre o crescimento econômico. Oliveira, Jacinto e Marques Junior (2006), em pesquisa mais abrangente, aplicaram o estudo para as cidades brasileiras na década de 1990 e averiguaram uma importante influência do governo no crescimento econômico, por meio dos investimentos.

Rocha e Giuberti (2005) estudaram a ligação entre o crescimento econômico e os componentes dos gastos do governo de maneira mais agregada para os estados brasileiros. Utilizaram o período de 1986 a 2002, e encontraram uma relação positiva entre o crescimento e os gastos com educação, defesa, transporte e comunicação. No entanto, ao aplicarem a relação das despesas totais/PIB com o PIB per capita, a relaçáo foi negativa.

Conclui-se que os estudos nacionais e internacionais, em diferentes escopos territoriais e hierárquicos, apresentam resultados diversos. Alguns apontam para a existência de uma relaçáo direta entre as políticas de gastos e investimentos e 
o crescimento econômico, de acordo com a proposta de Barro (1990), enquanto outras pesquisas mostram uma relação fraca, nula e até negativa desse fator como estímulo ao crescimento econômico. No que concerne a este trabalho, seu objetivo - e principal contributo - é, por meio da aplicação de uma metodologia rigorosa, realizar testes para se verificar a relação entre o crescimento e os gastos nos municípios do estado de Alagoas.

\section{METODOLOGIA}

Conhecida pela eficiência para lidar com séries temporais e cross-section ao mesmo tempo, a metodologia econométrica escolhida na presente pesquisa constou de modelo de dados em painel estático e do método de mínimos quadrados generalizados (painel dinâmico). $\mathrm{O}$ intuito era chegar a um modelo econométrico que permitisse a obtenção de resultados confiáveis e análises mais precisas do crescimento econômico em 102 municípios alagoanos ao longo do período de 2000 a 2015.

Um modelo tradicional de dados em painel apresenta a seguinte especificação:

$$
Y_{i t}=a_{i t}+X_{i t} \beta+\varepsilon_{i t} \text {. }
$$

Em que $Y_{i t}$ é a variável dependente, $a_{i t}$ é o componente fixo que capta a heterogeneidade das unidades em análise, $X_{i t}$ representa as variáveis explicativas, $\beta$ são os parâmetros a serem estimados e o termo de erro é representado por $\varepsilon_{i t}$.

Quando existe total disponibilidade de informaçóes para cada ponto no tempo $t$ correspondente a cada unidade $i$, diz-se que o painel é balanceado. Mas, na ausência de algumas dessas informaçóes, assume-se que o painel é desbalanceado.

O painel pode ser caracterizado como estático ou dinâmico. A metodologia de dados em painel estático pode ser subdividida em dois modelos: $i$ ) o efeito fixo (EF); e ii) o efeito aleatório (EA). No primeiro modelo, busca-se controlar as variáveis omitidas que são variantes entre as unidades, mas constantes ao longo do tempo. Dessa forma, pressupóe-se que as variáveis explicativas não dependem dos termos de erro.

O modelo de efeito aleatório possui características semelhantes às do modelo de efeito fixo, diferindo em que, no modelo de EA, considera-se o $\mu_{i t}$ como aleatório, e semelhante ao termo de erro. Usa-se este modelo quando se admite que o erro composto não esteja correlacionado às variáveis explicativas, nesse caso, a $E\left(a_{i}, X_{i t}\right)=0$ e $E\left(\varepsilon_{i t}, X_{i t}\right) \neq 0$. Uma das vantagens deste modelo é a possibilidade de inclusão de variáveis constantes no tempo, como gênero, raça etc. A especificação para efeito aleatório é dada por:

$$
Y_{i t}=X_{i t}+\mu_{i t} \text {. }
$$


Em que:

$$
\mu_{i t}=\alpha_{i t}+\varepsilon_{i t}
$$

O método mais adequado pode ser escolhido a partir da aplicação do teste de Hausman, para se verificar a significância dos estimadores do modelo. Para este teste, assume-se, como hipótese nula, $\left(H_{0}\right)$, ausência de correlação entre o erro composto $\mu_{i t}$ e as variáveis explicativas $X_{i t}$. Logo, se a hipótese nula não for rejeitada, diz-se que o estimador de EA não é viesado - e este método é escolhido, e o outro, rejeitado. Porém, se $H_{0}$ for rejeitada, utiliza-se o método de EF.

O método utilizado nas regressões acima é o dos mínimos quadrados ordinários $(\mathrm{MQO})$. A inclusão de variáveis dummy no modelo de $\mathrm{EF}$ - necessárias à identificação do município - pode trazer consigo uma série de problemas, a saber: i) a diminuição de graus de liberdade quando há grande número de variáveis; ii) a provável presença de multicolinearidade entre os regressores; iii) o modelo MQO pode não conseguir identificar o impacto de variáveis que não se alteram no modelo, como sexo, cor ou etnia; e, por fim, iv) a violação da hipótese de que $\varepsilon_{i t} \sim N\left(0, \sigma^{2}\right)$. Por sua vez, a presença de variáveis dummy no modelo EA pode ser apenas uma forma de contornar o desconhecimento do econometrista sobre as variáveis omitidas do modelo. Ademais, existe o risco de os erros estarem autocorrelacionados, resultando em estimadores ineficientes. Por essas razóes, a abordagem dos mínimos quadrados generalizados é a mais adequada.

Outro artifício utilizado para evitar a obtenção de estimadores enviesados ou inconsistentes, pela presença de heterocedasticidade e/ou autocorrelação dos erros, é a transformação logarítmica nas variáveis, bem como a utilização de estimadores robustos para a matriz de variância e covariância dos erros. Em geral, estas correçóes resolvem tais problemas quando presentes, mas, às vezes, tais problemas são persistentes, e a utilização de uma nova abordagem é necessária.

Uma das críticas que se fazem quanto ao uso do painel estático é que ele é insuficiente para observar a dimensão temporal dos dados, além da possibilidade de se incorrer em problemas de endogeneidade, que acontecem quando variáveis independentes se correlacionam ao erro, tornando as regressóes enviesadas e inconsistentes. Quando a dimensão temporal se torna bem relevante à análise, emprega-se um elemento de natureza dinâmica ao modelo de painel de dados, como o desenvolvido por Arellano e Bond (1991) e Blundell e Bond (1998).

$$
Y_{i t}=a y_{i t-1}+X_{i t} \beta+\varepsilon_{i t} \text {. }
$$

Nesse caso, $Y_{i t}$ é a variável dependente; $a y_{i t-1}$ corresponde à inclusão da variável dependente como explicativa defasada em um período; o vetor de variáveis explicativas $X_{i t}$ tem dimensão $(n \times k)$, enquanto o vetor do coeficiente $\beta$ possui dimensão $(k \times 1)$; e $\varepsilon_{i t}$ representa o termo de erro. 
De acordo com Arellano e Bond (1991), para o modelo dinâmico é proposto o estimador de GMM (sigla em inglês para generalized method of moments - método de momentos generalizados), com a seguinte forma:

$$
y_{i t}=\alpha y_{i t-1}+\beta^{\prime} x_{i t}+n_{i}+v_{i}=\delta^{\prime} x_{i t}+n_{i}+v_{i} .
$$

Em que:

$$
\hat{\delta}=\left(\Delta x^{\prime} z A_{n} z^{\prime} \Delta x\right)^{-1} \Delta x^{\prime} z A_{n} z^{\prime} \Delta y .
$$

Em que o efeito não observado específico à unidade $i$ é representado por $n_{i}$, enquanto o $v_{i t}$ corresponde ao erro global. Assume-se que a soma dos termos seja igual ao componente de erro, $n_{i}+v_{i}=\varepsilon_{i t}$, isto é, a composição do erro apresenta elementos ortogonais que representam os efeitos individuais fixos constantes no tempo e componente aleatório idiossincrático. A matriz de instrumentos é representada por $Z$, sendo estes defasagens da variável dependente; $A_{n}$ é a matriz que efetua o ajustamento das primeiras diferenças das variáveis aos instrumentos.

Arellano e Bond (1991) ressaltam que a consistência dos estimadores depende estritamente da qualidade dos instrumentos, e principalmente da maneira como estes são combinados com a primeira diferença das variáveis e com a suposiçáo da ausência de autocorrelação serial. Desse modo, uma condição necessária a ser considerada é a qualidade da matriz de instrumentos, pressupondo-se que $E\left(z^{\prime} \Delta v_{i}\right)=0$.

Para verificar a validade dos instrumentos escolhidos, Arellano e Bond (1991) propóem a aplicação do teste de Sargan, assumindo como hipótese nula $H_{0}: E\left(z^{\prime} \Delta v_{i}\right)=0$, que garante a validade da matriz de instrumentos.

Entretanto, de acordo com Blundell e Bond (1998), em painéis com dimensão temporal pequena, o problema de endogeneidade poderá persistir, bem como os instrumentos poderão apresentar-se fracos e enviesados. Dessa forma, os autores sugeriram a composição de um sistema que combine a utilização da variável dependente com defasagem de um período como variável explicativa, juntamente com instrumentos das equaçóes em nível com os valores defasados das primeiras diferenças das demais variáveis explicativas.

Para suavizar o problema de dimensão da amostra e tornar as estimativas mais precisas, Blundell e Bond (1998) integraram ao estimador a condição inicial, garantindo que $E\left(v_{i} \Delta y_{i(t=2)}\right)=0$ para todo $i$.

Assim, o estimador de Blundell e Bond (1998) assume a seguinte estrutura:

$$
y_{i t}=\alpha y_{i t-1}+\beta^{\prime}{ }_{1} x_{i t}+\beta^{\prime}{ }_{2} x_{i t-1}+n_{i}+v_{i}=\alpha^{\prime} x_{i t-1}+n_{i}+v_{i} \text {. }
$$


Em que:

$$
\hat{\alpha}=\left(\Delta y_{-1}^{\prime} z A_{n} z^{\prime} \Delta y_{-1}\right)^{-1} \Delta y_{-1} z A_{n} z^{\prime} \Delta y .
$$

Logo, para alcançar os resultados pretendidos neste trabalho, o painel de dados foi regredido nos três métodos. Primeiramente, no estimador de efeito fixo ou aleatório, tendo sido a escolha do melhor estimador determinada com o teste de Hausman; posteriormente, regrediram-se os estimadores como GMM nas formas difference e system. O GMM - Diff é o proposto por Arellano e Bond (1991) e inclui a primeira diferença à equação anterior, em que, para se garantir a eficiência dos estimadores, admite-se que o termo de erro é conhecido por $\varepsilon_{i t}=\mu_{i}+v_{i t} \mathrm{e}$ que $E\left(\mu_{i} v_{i t}\right)=0$. No entanto, aplicando-se apenas a primeira diferença, pode ocorrer a persistência dos problemas de endogeneidade e autocorrelação. Dessa forma, o GMM - System, modelo proposto por Blundell e Bond (1998), sugere a aplicação dos valores defasados das primeiras diferenças das variáveis como instrumento das equaçóes em níveis. Para identificar a consistência dos estimadores, precisa-se conhecer a qualidade dos instrumentos. Desse modo, a validade dos instrumentos será observada com o teste de Sargan.

\section{MODELOS PROPOSTOS}

A fim de se cumprir o propósito deste trabalho, que é o de testar o efeito da política fiscal sobre o crescimento dos 102 municípios do estado de Alagoas, construiu-se um painel de dados, que serviu de base às estimaçóes dos três modelos de crescimento propostos. As fontes dos respectivos dados foram órgãos oficiais, e o corte temporal considerado neste estudo se estende de 2000 a 2015, pois 2015 foi o ano mais recente com disponibilidade de informaçóes. No período entre 2003 e 2015 , o governo brasileiro esteve sob a presidência de Lula da Silva e Dilma Rousseff, ambos com propostas voltadas para uma política mais intervencionista de estímulo ao consumo, ao crédito e à distribuição de renda.

O painel de dados obtido possui uma dimensão 102 x 16, resultando num total de 1.632 observaçóes. Para as análises estatísticas, usamos o pacote "plm" (Croissant e Millo, 2008), da plataforma computacional R. ${ }^{5}$

Ao todo, três modelos econométricos foram obtidos. O primeiro deles, em painel estático, considerando-se as propostas teóricas apontadas pela NGE abordadas por Krugman (1991) e pela teoria de crescimento endógeno por Barro e Sala-i-Martim (1995), baseando-se ainda em alguns importantes estudos empíricos, como Oliveira (2006) e Costa, Lima e Silva (2014). Os outros dois foram modelos dinâmicos propostos por Arellano e Bond (1991) e Blundell e Bond (1998). São eles:

5. Disponível em: <https://www.R-project.org/>. 
Estático:

$$
\operatorname{lnPibpc}_{i t}=\alpha_{i}+\text { lndens }_{i t} \beta_{1}+\operatorname{lnct}_{i t} \beta_{2}+\operatorname{lnppibind}_{i t} \beta_{3}+\operatorname{lnpec}_{i t} \beta_{4}+\operatorname{lnpss}_{i t} \beta_{5}
$$

GMM

$$
\begin{gathered}
+\operatorname{lnphu}_{i t} \beta_{6}+\operatorname{lnpap}_{i t} \beta_{7}+\operatorname{lnpiss}_{i t} \beta_{8}+\operatorname{lnpiptu}_{i t} \beta_{9}+\varepsilon_{i t} \\
\operatorname{lnPibpc}_{i t}=\Delta \operatorname{sinPibpc}_{i t-1}+\Delta \operatorname{lndens}_{i t} \beta_{1}+\Delta \operatorname{lnct}_{i t} \beta_{2}+\Delta \text { lnppibind }{ }_{i t} \beta_{3}
\end{gathered}
$$

- Diff e

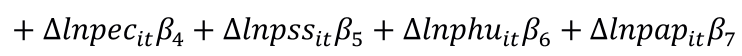

System:

$$
+\Delta \text { lnpiss }_{i t} \beta_{8}+\Delta \text { lnpiptu }_{i t} \beta_{9}+\Delta \varepsilon_{i t}
$$

As variáveis dependentes e os regressores estão descritos na tabela 1. Os betas $(\beta)$ representam os coeficientes de explicação encontrados para cada variável, o $i$ refere-se a cada município incluído no painel, $t$ representa os períodos correspondentes entre 2000 e 2015 e $\varepsilon_{i t}$ diz respeito ao termo de erro. Todos os dados se referem aos municípios alagoanos.

\section{TABELA 1}

\section{Descrição e fonte das variáveis de estudo}

\begin{tabular}{lll}
\hline Variáveis & Descrição & Fonte \\
\hline PIBpc & PIB per capita dos municípios; valores deflacionados pelo INPC, ano-base 2000. & IBGE \\
Dens & Densidade demográfica de cada município & IBGE \\
Ppinind & Proporção do PIB industrial em relação ao PIB municipal & IBGE \\
Ct & Custo de transporte municipal (proxy) & ANP e IBGE \\
Piptu & Proporção da arrecadação anual do IPTU em relação ao total das receitas orçamentárias. & Ipeadata e Siconfi \\
Piss & Proporção da arrecadação anual do ISSQN total das receitas orçamentárias. & Ipeadata e Siconfi \\
Pec & Proporção do gasto anual em educação e cultura em relação ao total das despesas empenhadas. & Ipeadata e Siconfi \\
Pss & $\begin{array}{l}\text { Proporção do gasto anual em saneamento e saúde em relação ao total das despesas empe- } \\
\text { nhadas. }\end{array}$ & Ipeadata e Siconfi \\
Phu & Proporção do gasto anual em habitação e urbanismo em relação ao total das despesas empenhadas. & Ipeadata e Siconfi \\
Pap & $\begin{array}{l}\text { Proporção do gasto anual em assistência e previdência em relação ao total das despesas } \\
\text { empenhadas. }\end{array}$ & Ipeadata e Siconfi \\
\hline i & Varia de 1 a 102 . Representa o número de municípios do modelo. & \\
\hline
\end{tabular}

Elaboração dos autores.

Obs.: IBGE - Instituto Brasileiro de Geografia e Estatística; IPTU- Imposto Predial Territorial e Urbano; ISSQN - Imposto sobre Serviços de Qualquer Natureza; Siconfi - Sistema de Informações Contábeis e Fiscais do Setor Público Brasileiro.

Observe-se que, para resultados mais consistentes, o PIB per capita foi deflacionado a partir do Índice Nacional de Preços ao Consumidor (INPC), assumindo-se 2000 como o ano-base; e que, com o intuito de observar o efeito das concentrações industriais, construiu-se a relação entre o PIB da indústria e o PIB dos municípios. Por seu turno, na construção da variável custo de transporte 
municipal $(C t)$, buscou-se averiguar o custo médio do deslocamento de cada município para a capital do estado. Para este feito, usou-se uma proxy que é o produto do custo médio da gasolina estadual no ano $i$ pela distância (em quilômetros) até Maceió, a capital do estado. A variável densidade demográfica foi elaborada a partir da razão entre a população residente em cada município e sua extensão territorial em quilômetros quadrados, considerando-se todas as alteraçóes de áreas e de população divulgadas pelo IBGE durante o período analisado.

Para as variáveis de controle, de despesas (Educação e Cultura; Saúde e Saneamento; Assistência e Previdência; e Habitação e Urbanismo) e de receita (IPTU e ISSQN), foi extraída a proporção de cada uma delas em relação ao total de despesas empenhadas num dado ano (ou das receitas orçamentárias, quando fosse o caso).

Sobre o comportamento das variáveis nos modelos estimados, esperava-se que o impacto das variáveis Piptu e Piss sobre o crescimento fosse negativo, inicialmente. Entretanto, sabe-se que este comportamento pode se mostrar ambíguo em relação ao sentido da resposta e do sinal. Por um lado, esperar-se-ia um efeito negativo sobre a taxa de crescimento, devido à contração dos gastos por parte dos agentes econômicos (IPTU), uma vez que os recursos são destinados a pagamento de tributos. Por outro lado, poderia ter um efeito positivo pelo crescimento do setor da construção civil, na medida em que novos imóveis representam aquecimento dessa atividade. Do lado dos serviços, o efeito poderia ser positivo, devido ao indicativo de crescimento do setor e ao aumento da arrecadação. Outros fatores que influenciam o crescimento econômico por meio dessas duas variáveis podem ainda ser elencados - por exemplo, a redução do emprego industrial e a migração para atividades de serviços. Assim, deixemos em aberto o que se espera dessas duas variáveis.

No que diz respeito aos gastos com educação e cultura, acredita-se que o direcionamento de recursos para esse segmento possuiria um resultado positivo sobre o produto, dado que impacta positivamente a produtividade dos trabalhadores. De igual modo, espera-se um efeito positivo dos gastos com saúde e saneamento sobre a taxa de crescimento, por refletir o impacto de grandes obras de infraestrutura, como redes de esgoto e hospitais, que exercem efeitos multiplicadores diretos e indiretos sobre o gasto público e o das famílias.

Sobre os gastos com habitação e urbanismo, espera-se também uma relação positiva, pelo efeito multiplicador provocado na economia. De maneira similar, espera-se o mesmo efeito dos gastos com assistência e previdência social, que são transferidos diretamente à populaçáo com maior propensão marginal a consumir, gerando resultados mais extensos. 


\section{RESULTADOS E ANÁLISES}

$\mathrm{Na}$ coleta de dados, observou-se a ausência de informaçóes para alguns municípios pesquisados. Principalmente no que tange aos gastos e às receitas municipais, como a arrecadação de IPTU (150 observaçôes ausentes), seguida pelas despesas (138 dados náo disponíveis para cada tipo de despesa). Logo, tem-se um painel desbalanceado.

Inicialmente, o modelo construído foi o de painel estático, considerando-se tanto os efeitos fixos quanto aleatórios. A escolha entre os dois se deu pela aplicação do teste de Hausman, descrito anteriormente. Se o valor- $p$ for significativo (por exemplo, <0,05), deve-se escolher o modelo de efeitos fixos; caso contrário, escolher-se-á o de efeitos aleatórios. No modelo construído, o valor para esse teste foi de $\chi^{2}=72,435$, com 9 graus de liberdade $(g l)$, resultando num valor- $p<0,0001$, o que indica o modelo de efeitos fixos (EF) como o mais adequado.

Ainda sobre o modelo EF, aplicamos o teste de Breush-Pagan LM e o teste de Pasaran CD para verificar dependência transversal (cross-sectional), sendo a hipótese nula, em ambos os testes, que os resíduos entre os municípios não são correlacionados. Mesmo a literatura afirmando que se trata de um problema relativamente pequeno em séries temporais pequenas e com grande número de indivíduos, sabe-se que essa dependência transversal pode levar a um viés nos resultados dos testes (também chamado de correlação contemporânea). Sendo assim, os resultados obtidos nesses testes foram $\chi^{2}=14.417$, com $g l=5.044$ e valor- $p<$ $2,2 e-16$, e $z=74.146$, valor- $p<2.2 e-16$, respectivamente. Assim, conclui-se que existe dependência transversal entre os municípios.

Ademais, testes para identificação da presença da heterocedasticidade e de autocorrelaçâo dos erros também foram aplicados ao modelo EF. O teste de Breusch-Pagan, com erros estudentizados (versão Koenker), gerou os seguintes resultados: $B P=309,63, g l=9$, valor $-p<2.2 e-16$, ou seja, os erros são heterocedásticos. Por sua vez, o teste de Breusch-Godfrey/Wooldridge para correlação serial em dados de painéis resultou em $\chi^{2}=327,31, g l=3$ e valor- $p<2,2 \mathrm{e}-16$, indicando a existência de correlação serial nos erros.

Com esses problemas identificados, buscou-se encontrar uma solução para resolver o problema da heterocedasticidade e da autocorrelação, utilizando-se o estimador Arelanno, de Arellano e Bond, que se mostrou o mais adequado e eficiente para o cálculo da matriz robusta de covariância, em se tratando de modelos de efeitos fixos. Assim, o primeiro modelo mostrado na tabela 2 já se encontra devidamente tratado.

$\mathrm{Na}$ construção dos dois modelos seguintes, a diferença é o estimador utilizado, que depende diretamente da qualidade dos instrumentos escolhidos. Este pode ser um dos problemas mais sérios ao se optar pelo método GMM, seja ele na 
versão diff ou system. Mesmo os criadores desses métodos sugerindo formas para esses instrumentos, sempre existirá uma infinidade de variáveis instrumentais que poderiam ser utilizadas caso a caso. De todo modo, a validade dos instrumentos sempre poderá ser averiguada por meio da aplicação do teste de Sargan, obtendo-se a rejeição da hipótese nula de correlação entre os instrumentos adicionais e o termo de erro. Os resultados obtidos estão dispostos na tabela 2.

Além do teste de Sargan, os testes F e de Wald, bem como o de autocorrelação de $1^{\underline{a}}$ ordem, também são apresentados para os modelos 2 e 3 . Os testes $\mathrm{F}$ e de Wald servem para testar a hipótese de que todos os coeficientes estimados no modelo são simultaneamente nulos, ou seja, que o modelo não existe. Esses testes verificam o modelo como um todo, e em todos os modelos existentes. Assim, a regressão se mostrou válida, com valores de $p$ inferiores a 2,22e-16.

TABELA 2

Efeito da política fiscal sobre o crescimento econômico

\begin{tabular}{|c|c|c|c|}
\hline Variáveis & $\begin{array}{l}\text { Modelo } 1 \\
\text { EF }\end{array}$ & $\begin{array}{l}\text { Modelo } 2 \\
\text { GMM-DIFF }\end{array}$ & $\begin{array}{l}\text { Modelo } 3 \\
\text { GMM-SYS }\end{array}$ \\
\hline $\operatorname{LnPibpc}_{t-1}$ & Não se aplica & $0,6594874^{* * *}$ & $0,9370547^{* * *}$ \\
\hline LnDens & $-0,0821179$ & $-0,3050857$ & 0,0446281 ** \\
\hline LnPPiblnd & $-0,1015068^{* * *}$ & 0,0319382 & $0,0174616^{* *}$ \\
\hline $\mathrm{LnCt}$ & $-0,4725907^{* * *}$ & $0,2226920^{* *}$ & $0,0447631^{* * *}$ \\
\hline LnPiptu & $-0,0293666 * * *$ & $-0,0118498$ & $-0,0049911$ \\
\hline LnPiss & $0,0720450^{* * *}$ & $0,0443777^{* * *}$ & 0,0056950 \\
\hline $\mathrm{LnPec}$ & $0,2711667^{* * *}$ & $0,2038841^{* * *}$ & $-0,0549780^{*}$ \\
\hline LnPss & $-0,0133397$ & $-0,1400809^{* * *}$ & $-0,0572102^{* *}$ \\
\hline LnPhu & $-0,0514771 * * *$ & $-0,0233266^{*}$ & $-0,0038417$ \\
\hline LnPap & $0,0661245^{* * *}$ & 0,0025335 & $-0,0070643$ \\
\hline Número de municípios & 102 & 102 & 102 \\
\hline \multicolumn{4}{|c|}{ Testes de especificação } \\
\hline$R^{2}$ & 0,284 & Não se aplica & Não se aplica \\
\hline$R^{2}$ & 0,223 & Não se aplica & Não se aplica \\
\hline$F_{9 ; 1277}$ & $52,21^{* * *}$ & Não se aplica & Não se aplica \\
\hline Teste de Sargan & Não se aplica & $91,165^{*}$ & $86,090^{*}$ \\
\hline $\begin{array}{l}\text { Teste de autocorrelação de } \\
\text { 1a ordem }\end{array}$ & Não se aplica & $-4,227^{* * *}$ & $-4,133^{* * *}$ \\
\hline Teste Wald & Não se aplica & $291,081 * * *$ & 3920846 ** \\
\hline
\end{tabular}

Elaboração dos autores.

Obs.: 1. Códigos para níveis de significância: *** 0,$001 ;{ }^{* *} 0,01 ;{ }^{*} 0,05 ;{ }^{*} \cdot ; ; 0,1 ;{ }^{\prime \prime} 1$.

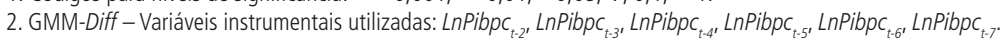

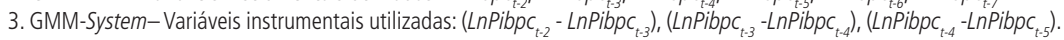


O teste de autocorrelação de $1^{a}$ ordem se faz necessário para testar a hipótese de um erro de um determinado período estar correlacionado com o erro do período imediatamente anterior. Porém, isto não se verificou em nenhum dos três modelos estimados.

\subsection{Interpretação dos modelos}

\subsubsection{Modelo 1 - Painel estático com efeitos fixos}

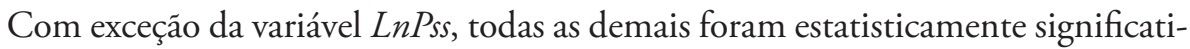
vas, mostrando que os respectivos parâmetros possuem capacidade de influenciar

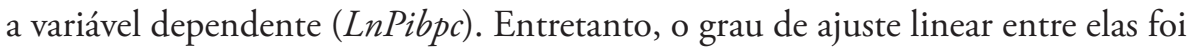
pequeno $\left(R^{2}=0,284\right)$, sugerindo que talvez um novo ajuste devesse ser tentado com o intuito de se obterem melhores resultados.

A forma de interpretar os parâmetros deste modelo é simples, o que torna a modelagem $\log$ - $\log$ bastante útil. Segundo o modelo EF, um incremento de $1 \%$ nas variáveis densidade demográfica, proporção do PIB industrial, custo de transporte, peso nas receitas com a arrecadaçẫo do IPTU e despesas com habitação e urbanismo provocaria diminuiçóes de $0,082 \%, 0,102 \%, 0,473 \%, 0,030 \%$, e $0,051 \%$, respectivamente, no crescimento econômico per capita dos municípios. Da mesma forma, um aumento de $1 \%$ nos regressores proporção nas receitas com a arrecadação do ISSQN, gastos com educaçáo e cultura e assistência e previdência social de um município, provocaria acréscimos de 0,072\%, 0,271\% e 0,066\%, respectivamente, no crescimento econômico per capita. A variável $L n P_{s s}$ não foi estatisticamente significativa, o que não permite nenhuma inferência a respeito da sua influência sobre o PIB per capita municipal.

Os maiores efeitos podem ser percebidos nas seguintes variáveis: custo de transporte, pois, quanto mais longe da capital alagoana, maior o impacto negativo no crescimento econômico per capita; e nos gastos com educação e cultura, em que o aumento de $1 \%$ geraria um impacto positivo de aproximadamente $0,3 \%$ no crescimento econômico per capita.

\subsubsection{Modelos 2 e 3 - Painel dinâmico com transformação nos dados tipo Difference e System}

Para a variável dependente inclusa com defasagem como variável explicativa em ambos os modelos, observam-se resultados estatisticamente significantes para a primeira defasagem, com sinal positivo, mostrando que, quanto maior o PIB per capita do período anterior, maior será o PIB per capita do período seguinte.

Sobre a significância estatística, para os estimadores do painel dinâmico do tipo GMM-DIFF, apresentam-se estatisticamente significantes as variáveis: custo de transporte, proporção do PIB industrial, proporção do ISSQN nas receitas, e gastos com educação e cultura, saúde e saneamento, habitação e urbanismo. 
No modelo tipo GMM-System, as variáveis densidade demográfica, proporção do PIB industrial, custo de transporte, e os gastos com educação e cultura, saúde e saneamento foram estatisticamente significativos. Observe-se que duas variáveis foram estatisticamente significativas nos três modelos - $L n C t$, e $L n P e c-$, reforçando a importância desses regressores em modelos de crescimento econômico.

A interpretação dos parâmetros estimados na abordagem GMM é a mesma apresentada para o modelo EF. Incrementos de $1 \%$ nos regressores provocam aumentos/reduçóes de $\widehat{\beta} \%$ a depender do sinal $([+]$ significa relação direta, ou seja, quando o regressor aumenta, a variável dependente aumenta; [-] significa uma relação inversa).

Considerando-se que a abordagem GMM System é a mais confiável em termos econométricos, por razōes já expostas neste trabalho, vamos nos concentrar um pouco mais sobre ela, em detrimento das demais modelagens apresentadas.

No que concerne aos sinais esperados, notou-se que, das seis variáveis estatisticamente significativas - PIB per capita defasado em um ano $\left(\operatorname{LnPibpc}_{t-1}\right)$, densidade demográfica (LnDens), proporção do PIB industrial (LnPPibInd), custo de transporte $(L n C t)$, e os gastos com educaçáo e cultura $(L n P e c)$, saúde e saneamento $(L n P s s)$, três obtiveram sinais convergentes à teoria (Pibpc $c_{t-1}$, Dens e PPibInd). Quanto maior o PIB per capita do período anterior, a densidade demográfica e a proporção do PIB industrial no PIB total em determinado município, maior o crescimento econômico per capita.

A proporção do PIB da indústria em relação ao PIB municipal apresentou coeficiente positivo e significante ao nível de $99 \%$ de confiança. Esta relação se propóe a captar o efeito da concentraçáo industrial sobre o crescimento. Os resultados obtidos apontam que concentraçóes industriais favorecem o surgimento de novas indústrias, por promoverem benefícios e interaçôes. As inovaçôes tecnológicas ocorrem com maior intensidade nestes ambientes via transbordamentos, fluindo trocas de conhecimento e mão de obra qualificada. O resultado é um efeito positivo sobre o crescimento econômico das economias de aglomeraçáo e de localização. Conforme destaca Ruiz (2006), os maiores PIBs per capita e os menores custos de vida se encontram nas regiôes mais industrializadas.

De acordo com a NGE, o nível populacional de uma regiáo pode impactar o seu desempenho como uma força centrífuga ou centrípeta. Atua como força centrífuga quando grande concentração populacional afeta negativamente o crescimento econômico, desestimulando os investimentos por parte do setor privado, uma vez que a aglomeração populacional produz pobreza, poluição e criminalidade - efeito não observado no presente estudo. Por outro lado, uma maior densidade populacional pode atuar como força centrípeta, distorcendo 
esse efeito, tornando-se estímulo à instalação de novas indústrias, devido ao excesso de mão de obra barata. Este fenômeno ativa o efeito multiplicador, afetando positivamente o crescimento econômico por meio da geração de emprego, renda e consumo.

Neste estudo, notou-se que a variável densidade demográfica no painel dinâmico obteve coeficientes positivos, estatisticamente significativos ao nível com $99 \%$ de confiança. Isso indica que a concentração populacional nos municípios de Alagoas atua como força centrípeta, afetando positivamente o crescimento econômico e estimulando os investimentos do setor privado.

Entretanto, outras duas variáveis ( $\operatorname{nnPec}$ e $\operatorname{LnPss}$ ) divergiram totalmente da intuição econômica. Alguns autores que verificaram a relação das despesas com saúde chegaram a resultados semelhantes, como Rocha e Giuberti (2005), que também obtiveram um efeito negativo, e Kormendi e Meguire (1985) e Easterly e Rebelo (1993), que mostraram impactos nulos. Todavia, é no mínimo curioso que, mesmo com elevados percentuais de gastos nas rubricas de educação e saúde (nem tanto em saneamento e cultura) - as quais incluem, entre outras coisas, construçôes de escolas e hospitais -, esses dispêndios não exerçam um impacto positivo sobre o crescimento.

Silva, Cruz e Irffi (2013) encontraram resultados próximos aos obtidos nas regressões do presente trabalho. Os resultados do estudo para a Paraíba mostraram que as despesas com educação e cultura, saúde e saneamento e habitação e urbanismo têm baixa elasticidade-produto, influenciando de forma moderada o crescimento.

Estudos que investiguem melhor a eficiência dos gastos e a eficácia alocativa dos recursos empregados nessas rubricas são necessários. Talvez uma explicação razoável seja que boa parte dos recursos aplicados nessas duas rubricas tenham sido direcionados para custeio, e não para capital, ou ainda que a variação percentual dos gastos nessas pastas, durante o período em questão, tenha oscilado apenas marginalmente, mantendo-se próxima ao estipulado por lei.

\section{CONSIDERAÇÕES FINAIS}

O objetivo central deste estudo foi testar os efeitos da política fiscal elaborada pelas prefeituras dos municípios do estado de Alagoas, e como esta se relaciona com o crescimento. Para tanto, utilizou-se um modelo econométrico de painel estático e outros dois de painel dinâmico, abrangendo o período de 2000 a 2015. Desse modo, foi possível observar de maneira consistente a eficiência das açóes do governo sobre o crescimento econômico dos 102 municípios do estado de Alagoas. 
Para se chegar a essa conclusão, foram aplicadas três modelagens econométricas à mesma base de dados, ressaltando-se que os resultados diferem nos modelos econométricos. Devido à natureza dos dados e da aplicação dos testes de especificação, apontou-se como mais adequada a utilização da técnica para dados em painel dinâmico, estimados pelo GMM do tipo system, uma vez que este corrige o problema de endogeneidade nas variáveis utilizadas nesta pesquisa, e possui um estimador muito mais eficiente para a estimação dos $\beta$ s do que o dos outros dois modelos.

Sobre os gastos em educação, cultura, saúde e saneamento, foram obtidos resultados contraintuitivos ao proposto pela teoria elencada. Esperava-se que esse tipo de gasto promovesse não somente melhorias na qualidade de vida das pessoas, mas contribuísse para a elevação no nível do produto. No entanto, no caso de Alagoas, o resultado se mostrou ainda menos intuitivo, com essas variáveis apresentando impacto negativo em relação ao crescimento per capita do estado. Resultado que, apesar de surpreendente, já fora encontrado por outros pesquisadores, em maior ou menor grau, em trabalhos sobre o mesmo tema. Talvez uma maneira de solucionar esse "mistério" seja o emprego de uma modelagem econométrica que utilize os componentes desagregados desses gastos, para se verificar como são distribuídos e em quais rubricas.

No que diz respeito à política tributária, os coeficientes obtidos para as variáveis LnPiptu e LnPiss, além das despesas com habitação, urbanismo, assistência e previdência social, apresentaram-se estatisticamente insignificantes. Este fato impossibilita-nos de realizar inferências sobre a relação existente entre essas receitas e despesas na trajetória de crescimento econômico. Uma possível explicação seria a baixa eficácia desses itens na arrecadação dos municípios, ou mesmo sua pouca relevância nas receitas e despesas totais.

Verificou-se também um resultado coerente com a literatura a respeito da variável para o custo de transporte, ou seja, foi confirmado, pelo terceiro modelo, que esta variável gera um efeito negativo sobre o crescimento econômico per capita.

Por fim, observou-se que a variável densidade demográfica para os municípios analisados atua como força centrípeta. Em outras palavras, o fato de os municípios possuírem maior concentração populacional afetaria positivamente o crescimento econômico, estimulando os investimentos do setor privado, como defendido pela nova geografia econômica. Da mesma maneira, este trabalho permite aos policymakers fazerem inferências sobre a importância de governos municipais direcionarem esforços no incentivo ao fortalecimento de centros industriais, pois estes estimulam os investimentos e o crescimento econômico regional. 


\section{REFERÊNCIAS}

ARAUJO, J. A.; MONTEIRO, V. B.; MORAIS, G. A. S. Gastos públicos e crescimento econômico: evidências da economia do estado do Ceará. Revista Ciências Administrativas, Fortaleza, v. 20, n. 1, p. 11-40, jan./jun. 2014.

ARELLANO, M.; BOND. S. Some tests of specification for panel data: Monte Carlo evidence and an application to employment equations. Review of Economic Studies, v. 58, p. 277-297, 1991.

ASCHAUER, D. Is public expenditure productive? Journal of Monetary Economics, v.23, p.177-200, 1989.

ATLAS DO DESENVOLVIMENTO HUMANO NO BRASIL. Disponível em: <http://www.atlasbrasil.org.br/2013/consulta/>. Acesso em: 2 fev. 2015.

BARRO, R. J. Economic growth in a cross section of countries. Quarterly Journal of Economics, v. 106, p. 407-443, 1990.

BARRO, R. J.; SALA-I-MARTIN, X. Economic growth. New York: McGraw Hill, 1995.

BLUNDELL, R.; BOND, S. Initial conditions and moment restrictions in dynamic panel data models. Journal of Econometrics, v. 87, p.115-143, 1998.

COSTA, R. F. R.; LIMA, F. S.; SILVA, D. O. P. Política fiscal local e taxa de crescimento econômico: um estudo com dados em painel. Revista Planejamento e Políticas Públicas, n. 42, jan./jun. 2014.

CROISSANT, Y.; MILLO, G. Panel data econometrics in R: the plm package. Journal of Statistical Software, v. 27, n. 2, p. 1-43, 2008.

EASTERLY, W.; REBELO, S. Fiscal policy and economic growth: an empirical investigation. Journal of Monetary Economics, n. 32, p. 417-458, 1993.

FERREIRA, P. C.; MALLIAGROS, T. G. Impactos produtivos da infraestrutura no Brasil: 1950-1975. Revista Pesquisa e Planejamento Econômico, n. 2, p. 315-338, 1998.

JONES, C. I. Introduçáo a teoria de crescimento econômico. 2. ed. Rio de Janeiro: Campus, 2000.

KNELLER, R.; BLEANEY, M.; GEMMEL, N. Testing the endogenous growth model: public expenditure, taxation and growth over the long run. The Canadian Journal of Economics, v. 34, n. 1, p. 36-57, 2001.

KORMENDI, R. C.; MEGUIRE, P. G. Macroeconomic determinants of growth. Journal of Monetary Econometrics, v. 16, p. 141-163, 1985. 
KRUGMAN, P. Increasing returns and economic geography. Journal of Political Economy, v. 99, n. 3, p. 483-499, 1991.

LUCAS, R. E. On the mechanics of economic development. Journal of Monetary Economics, v. 22, p. 3-42, 1988.

OLIVEIRA, C. A. Crescimento Econômico das cidades nordestinas: um enfoque da nova geografia econômica. Revista Econômica do Nordeste, Fortaleza, v. 35, n. 3, jul./set. 2004.

. Política fiscal local e o crescimento econômico dos municípios gaúchos (1996-2001). In: ENCONTRO DE ECONOMIA GAÚCHO, 3., 2006, Porto Alegre, Rio Grande do Sul. Anais... Porto Alegre: FEE, 2006.

OLIVEIRA, C. A.; JACINTO, P. A.; MARQUES JUNIOR, L. S. O papel da política fiscal local no crescimento econômico de cidades: uma evidência empírica para o Brasil. In: ENCONTRO REGIONAL DE ECONOMIA, 11., 2006, Fortaleza, Ceará. Anais... Fortaleza: Anpec, 2006.

ROCHA, F.; GIUBERTI, A. C. Composição do gasto público e crescimento econômico: um estudo em painel para os estados brasileiros. In: ENCONTRO NACIONAL DE ECONOMIA, 33., 2005, Natal. Anais... Natal: Anpec, 2005.

ROMER, P. Increasing returns and long run growth. Journal of Political Economy, v. 94, p. 1003-1037, 1986.

RUIZ, R. M. Políticas regionais na nova geografia econômica. In: DINIZ, C. C.; CROCCO, M. Economia regional e urbana: contribuiçóes teóricas recentes. Belo Horizonte: Editora da UFMG, 2006.

SILVA, L. D. C.; CRUZ, M. S.; IRFFI, G. Gastos públicos e crescimento econômico: uma análise para os municípios paraíbanos. Revista Econ.NE, Fortaleza, v. 44, n. 3, p. 741-760, jul./set. 2013.

SOLOW, R. A contribution to the theory of economic growth. Quarterly Journal of Economics, v. 70, n. 1, p. 65-94, 1956.

\section{BIBLIOGRAFIA COMPLEMENTAR}

GREENE, W. H. Econometric analysis. 5. ed. New Jersey: Prentice Hall, 2002. $285 \mathrm{p}$.

IBGE - INSTITUTO BRASILEIRO DE GEOGRAFIA E ESTATÍSTICA. Populaçáo. Disponível em: <https://bit.ly/2EuKtpS>. Acesso em: $1^{\circ}$ set. 2018.

. Indústria e construçáo. Disponível em: <https://bit.ly/31rsSrU>. Acesso em: $1^{\circ}$ set. 2018. 
SAMUELSON, P. A.; NORDHAUS, W. D. Economia. 19. ed. Portugal: McGraw-Hill, 2012.

SICONFI - SISTEMA DE INFORMAÇÕES CONTÁBEIS E FISCAIS DO SETOR PÚBLICO BRASILEIRO. Histórico de contas anuais. Disponível em: <https://bit.ly/32qWoxa>. Acesso em: 20 ago. 2018.

Data da submissão: 31/3/2017

Primeira decisão editorial em: 16/7/2018

Última versão recebida em: 12/9/2018

Aprovação final em: 24/9/2018 